\title{
Preoperative Chronic Kidney Disease as a Strong Predictor of Postoperative Infection and Mortality After Coronary Artery Bypass Grafting
}

Kenji Minakata, MD, PhD; Ko Bando, MD, PhD; Shiro Tanaka, PhD; Shuichiro Takanashi, MD, PhD; Hiroaki Konishi, MD, PhD; Yoshihiro Miyamoto, MD, PhD; Kenji Ueshima, MD, PhD;

Shinji Yasuno, MD, PhD; Yuichi Ueda, MD, PhD; Yutaka Okita, MD, PhD; Izuru Masuda, MD, PhD; Hitoshi Okabayashi, MD, PhD; Hitoshi Yaku, MD, PhD; Yoshitaka Okamura, MD, PhD;

Kazuo Tanemoto, MD, PhD; Koichi Arinaga, MD, PhD; Yosuke Hisashi, MD; Ryuzo Sakata, MD, PhD

\begin{abstract}
Background: The aim of this study was to determine the influence of preoperative kidney dysfunction (ie, chronic kidney disease (CKD)) on postoperative cardiovascular events, infection, acute kidney injury and hospital mortality in patients undergoing coronary artery bypass grafting (CABG).

Methods and Results: A multi-institutional retrospective study was performed at 14 hospitals of adult patients undergoing isolated CABG from 2007 to $2008(n=1,522)$. We classified CKD level according to preoperative estimated glomerular filtration rate (eGFR): normal, eGFR $>90 \mathrm{ml} \cdot \mathrm{min}^{-1} \cdot 1.73 \mathrm{~m}^{-2}$; mild, eGFR 60-90 $\mathrm{ml} \cdot \mathrm{min}^{-1} \cdot 1.73 \mathrm{~m}^{-2}$; moderate, eGFR $30-59 \mathrm{ml} \cdot \mathrm{min}^{-1} \cdot 1.73 \mathrm{~m}^{-2}$; and severe, eGFR $<30 \mathrm{ml} \cdot \mathrm{min}^{-1} \cdot 1.73 \mathrm{~m}^{-2}$, and assessed postoperative outcome. Preoperative CKD distribution was as follows: normal, $n=121$ (8\%); mild, $n=713(47 \%)$; moderate, $n=515$ (34\%); and severe, $\mathrm{n}=169$ (11\%). Risk of infection was strongly correlated with CKD level (normal, 3.3\%; mild, $7.0 \%$; moderate, $8.3 \%$; severe, $17.0 \%$; $\mathrm{P}<0.01$ ). The risk of in-hospital death was also strongly correlated with CKD level (normal, 1.7\%; mild, 1.0\%; moderate, 1.6\%; severe, $5.9 \%$; $\mathrm{P}<0.01$ ). On multivariate logistic regression analysis, CKD level was identified as a significant risk factor for postoperative infection, acute kidney injury, and in-hospital death.
\end{abstract}

Conclusions: Advanced preoperative CKD is a strong predictor of postoperative infection, acute kidney injury and in-hospital death after CABG. (Circ J 2014; 78: 2225-2231)

Key Words: Chronic kidney disease; Complication; Coronary artery bypass grafting; Infection; Mortality

$\mathbf{I}$ $t$ is well recognized that chronic kidney disease $(\mathrm{CKD})$ of any degree entails a worsened prognosis for patients with coronary artery disease (CAD).$^{1-7}$ In addition, CKD itself can accelerate atherosclerotic pathophysiology in patients with CAD, and the level of CKD is an independent predictor for CAD. ${ }^{2,3}$ It has also been reported that the presence of diabetes mellitus (DM), which is a leading cause of end-stage renal disease (ESRD), accelerates the disease process of CAD and decreases late survival in CKD patients. ${ }^{1,8}$ Advanced CKD is certainly a preliminary step towards ESRD, subsequently requiring renal replacement therapy such as hemodialysis (HD) or kidney transplant. ${ }^{9}$ In patients with ESRD, cardiovascular disease is definitely the leading cause of death, limiting long-term survival. ${ }^{10}$

\section{Editorial p2151}

There is a growing body of literature that supports the con-

Received March 18, 2014; revised manuscript received June 10, 2014; accepted June 15, 2014; released online July 25, 2014 Time for primary review: 22 days

Kyoto University Graduate School of Medicine, Kyoto (K.M., K.U., S.Y., R.S.); Jikei University School of Medicine, Tokyo (K.B.); Kyoto University School of Public Health, Kyoto (S. Tanaka); Sakakibara Heart Institute, Tokyo (S. Takanashi); Jichi Medical University, Shimotsuke (H.K.); National Cerebral and Cardiovascular Center, Suita (Y.M.); Nara Prefectural Hospital, Kashihara (Y.U.); Kobe University Graduate School of Medicine, Kobe (Y. Okita); Takeda Preventive Medicine and EBM Center, Kyoto (I.M.); Iwate Medical University, Morioka (H.O.); Kyoto Prefectural University of Medicine, Kyoto (H.Y.); Wakayama Medical University, Wakayama (Y. Okamura); Kawasaki Medical School, Kurashiki (K.T.); Kurume University School of Medicine, Kurume (K.A.); and Kagoshima University Graduate School of Medicine and Dental Science, Kagoshima (Y.H.), Japan

Mailing address: Kenji Minakata, MD, PhD, Department of Cardiovascular Surgery, Kyoto University Graduate School of Medicine, 54 Kawahara-cho, Shogoin, Sakyo-ku, Kyoto 606-8507, Japan. E-mail: minakata @kuhp.kyoto-u.ac.jp

ISSN-1346-9843 doi:10.1253/circj.CJ-14-0328

All rights are reserved to the Japanese Circulation Society. For permissions, please e-mail: cj@j-circ.or.jp 


\begin{tabular}{|c|c|c|c|c|c|}
\hline Variables & $\begin{array}{l}\text { Normal } \\
\text { eGFR >90 } \\
(n=121)\end{array}$ & $\begin{array}{l}\text { Mild CKD } \\
\text { eGFR 60-90 } \\
(n=713)\end{array}$ & $\begin{array}{c}\text { Moderate CKD } \\
\text { eGFR 30-59 } \\
(n=515)\end{array}$ & $\begin{array}{c}\text { Severe CKD } \\
\text { eGFR <30 } \\
(n=169)\end{array}$ & $P$ value \\
\hline Age (years) & $62.8 \pm 12.2$ & $67.2 \pm 9.0$ & $71.3 \pm 7.7$ & $69.2 \pm 8.8$ & $<0.01$ \\
\hline Age $\geq 75$ & $18(14.9)$ & $153(21.5)$ & $189(36.7)$ & $45(26.6)$ & $<0.01$ \\
\hline Male gender & $95(78.5)$ & 570 (79.9) & $386(75.0)$ & $124(73.4)$ & 0.03 \\
\hline eGFR $\left(\mathrm{ml} \cdot \mathrm{min}^{-1} \cdot 1.73 \mathrm{~m}^{-2}\right)$ & $112.6(99.8)^{\dagger}$ & $72.8(72.6)^{\dagger}$ & $49.1(50.7)^{\dagger}$ & $14.7(12.4)^{\dagger}$ & $<0.01$ \\
\hline $\mathrm{BMI}\left(\mathrm{kg} \cdot \mathrm{m}^{-2}\right)$ & $23.0 \pm 3.3$ & $23.7 \pm 3.1$ & $23.7 \pm 3.1$ & $23.1 \pm 3.6$ & 0.72 \\
\hline Hypertension & $76(62.8)$ & $520(72.9)$ & $389(75.5)$ & $142(84.0)$ & $<0.01$ \\
\hline Dyslipidemia & $58(47.9)$ & $432(60.6)$ & $311(60.4)$ & $71(42.0)$ & 0.10 \\
\hline $\mathrm{DM}$ & $51(42.1)$ & $351(49.2)$ & $297(57.7)$ & $112(66.3)$ & $<0.01$ \\
\hline On insulin & $13(10.7)$ & $91(12.8)$ & $83(16.1)$ & $50(29.6)$ & \\
\hline Preoperative HbA1c (\%) & $6.0 \pm 1.0$ & $6.1 \pm 1.1$ & $6.2 \pm 1.1$ & $6.1 \pm 1.1$ & 0.60 \\
\hline Preoperative steroid use & $1(0.8)$ & $9(1.3)$ & $12(2.3)$ & $6(3.6)$ & 0.02 \\
\hline $\mathrm{CHF}$ & $18(14.9)$ & $103(14.4)$ & $85(16.5)$ & $44(26.0)$ & $<0.01$ \\
\hline COPD & $16(13.2)$ & $52(7.3)$ & $43(8.3)$ & $21(12.4)$ & 0.54 \\
\hline PAD & $23(19.0)$ & $117(16.4)$ & $123(23.9)$ & $57(33.7)$ & $<0.01$ \\
\hline LVEF $<50 \%$ & $26(21.5)$ & $133(18.7)$ & $136(26.4)$ & $49(29.0)$ & $<0.01$ \\
\hline \multicolumn{6}{|l|}{ Operative status } \\
\hline Elective & $92(76.0)$ & $602(84.4)$ & $455(88.3)$ & $132(78.1)$ & 0.41 \\
\hline Urgent & $19(15.7)$ & $71(10.0)$ & $40(7.8)$ & $24(14.2)$ & \\
\hline Emergency & $10(8.3)$ & $40(5.6)$ & $20(3.9)$ & $13(7.7)$ & \\
\hline Bilateral ITA use & $63(52.1)$ & $373(52.3)$ & 218 (42.3) & $57(33.7)$ & $<0.01$ \\
\hline Intraoperative steroid use & $52(43.0)$ & $236(33.1)$ & $147(28.5)$ & $53(31.4)$ & 0.02 \\
\hline \multicolumn{6}{|l|}{ On-pump or off-pump } \\
\hline On-pump & $32(26.4)$ & $173(24.3)$ & $120(23.3)$ & $54(32.0)$ & 0.36 \\
\hline On-pump beating & 4 (3.3) & $28(3.9)$ & $18(3.5)$ & $6(3.6)$ & \\
\hline Off-pump & $85(70.2)$ & $512(71.8)$ & $377(73.2)$ & $109(64.5)$ & \\
\hline
\end{tabular}

Data given as mean $\pm \mathrm{SD}$, tmedian (eGFR) or $\mathrm{n}(\%)$. BMI, body mass index; CHF, congestive heart failure; CKD, chronic kidney disease; COPD, chronic obstructive pulmonary disease; DM, diabetes mellitus; eGFR, estimated glomerular filtration rate; LVEF, left ventricular ejection fraction; ITA, internal thoracic artery; PAD, peripheral artery disease.

tention that CKD is associated with poor prognosis for patients undergoing $\mathrm{CABG}, \mathbf{8 , 1 1 , 1 2}$ but it is not well understood exactly how CKD influences the outcome of CABG patients. We previously reported that the presence of DM itself was not a statistically significant risk factor for morbidity and mortality in patients undergoing $\mathrm{CABG}$, whereas preoperative advanced $\mathrm{CKD}$ was a much stronger independent risk factor for postoperative infection and in-hospital mortality. ${ }^{13}$ Here, we conducted sub-analyses as a host-hoc study to identify the significance of preoperative kidney dysfunction level, classified as estimated glomerular filtration rate (eGFR), on morbidity and mortality. Also, we assessed the impact of chronic HD on postoperative complications among severe CKD patients.

\section{Methods}

From January 2007 until December 2008, a total of 1,522 adult patients underwent isolated CABG in 14 cardiac surgery centers in Japan. Patients who underwent redo CABG were included, but patients who underwent concomitant procedures such as valvular procedures, aneurysm repair, arrhythmia surgery, repair of ventricular septal perforation, and surgical ventricular restoration procedures were excluded from this study. All the patient characteristics and operative data were extracted from the prospective national database (Japan Adult Cardiovascular Surgery Database: JACVSD), which is similar to the Society of Thoracic Surgeons (STS) national database in North America. Other study-specific data such as preoperative hemoglobin A1c and postoperative complications, including cardiovascular events and individual infections, which are not included in the JACVSD, were obtained from medical records at each study site. These 2 sets of data were merged, then blinded and sent to a data center (EBM Research Center, Kyoto University Graduate School of Medicine, Kyoto, Japan).

Demographic variables and their definitions have been described elsewhere. ${ }^{13}$ Preoperative CKD level was classified according to eGFR, calculated using the Modification of Diet in Renal Disease formula for Japanese patients: ${ }^{14}$

$$
\begin{aligned}
\operatorname{eGFR}\left(\mathrm{ml} \cdot \min ^{-1} \cdot 1.73 \mathrm{~m}^{-2}\right)= & 194 \times \text { serum creatinine } \\
& \times \text { age }^{-1.094} \times 0.739(\text { if female }) .
\end{aligned}
$$

Of note, the presence and level of proteinuria were not measured, and the cause of kidney dysfunction was also not considered in this study. CKD level was then classified only according to eGFR: normal (eGFR $>90 \mathrm{ml} \cdot \mathrm{min}^{-1} \cdot 1.73 \mathrm{~m}^{-2}$ ), mild CKD (eGFR 60-90 $\mathrm{ml} \cdot \mathrm{min}^{-1} \cdot 1.73 \mathrm{~m}^{-2}$ ), moderate CKD (eGFR $30-59 \mathrm{ml} \cdot \mathrm{min}^{-1} \cdot 1.73 \mathrm{~m}^{-2}$ ), and severe CKD (eGFR $\left.<30 \mathrm{ml} \cdot \mathrm{min}^{-1} \cdot 1.73 \mathrm{~m}^{-2}\right)$. DM patients were defined as those patients who were admitted to the participating hospitals with a diagnosis of DM. Also, patients without a previous diagnosis of DM who had preoperative hemoglobin A1c $\geq 6.5 \%$ (National Glycohemoglobin Standardization Program) were included.

Internal thoracic arteries (ITA) were harvested in a skeletonized fashion using the harmonic scalpel (Ethicon, West Somerville, NJ, USA) at most of the participating centers. In terms of intraoperative steroid use, a large amount of steroid 


\begin{tabular}{|c|c|c|c|c|}
\hline Events and outcomes & $\begin{array}{l}\text { Normal } \\
\text { eGFR >90 } \\
(n=121)\end{array}$ & $\begin{array}{c}\text { Mild CKD } \\
\text { eGFR 60-90 } \\
(n=713)\end{array}$ & $\begin{array}{c}\text { Moderate CKD } \\
\text { eGFR 30-59 } \\
(n=515)\end{array}$ & $\begin{array}{c}\text { Severe CKD } \\
\text { eGFR <30 } \\
(n=169)\end{array}$ \\
\hline Perioperative MI & $1(0.83)$ & $15(2.1)$ & $7(1.4)$ & $2(1.2)$ \\
\hline Related death & $1(0.83)$ & $2(0.28)$ & 0 & 0 \\
\hline Cerebrovascular events & $2(1.7)$ & $6(0.84)$ & $10(1.94)$ & $1(0.59)$ \\
\hline Related death & 0 & 0 & $1(0.19)$ & 0 \\
\hline Other cardiovascular events & $2(1.7)$ & $8(1.1)$ & $14(2.7)$ & $3(1.8)$ \\
\hline Related death & 0 & $1(0.14)$ & $3(0.48)$ & 0 \\
\hline Deep sternal wound infection & $1(0.83)$ & $6(0.84)$ & $9(1.75)$ & $9(5.3)$ \\
\hline All infection & $4(3.3)$ & $50(7.0)$ & $43(8.3)$ & $28(16.6)$ \\
\hline Related death & $1(0.83)$ & $2(0.28)$ & $2(0.39)$ & $8(4.7)$ \\
\hline Acute kidney injury & 0 & $3(0.42)$ & $9(1.7)$ & $7(4.1)$ \\
\hline Related death & 0 & $1(0.14)$ & 0 & 0 \\
\hline Postoperative ventilator time (h) & $19.0^{\dagger}$ & $26.4^{\dagger}$ & $33.8^{\dagger}$ & $56.7^{\dagger}$ \\
\hline In-hospital death & $2(1.7)$ & $7(0.98)$ & $8(1.6)$ & $10(5.9)$ \\
\hline
\end{tabular}

Data given as $\mathrm{n}(\%)$ or tmean. Ml, myocardial infarction. Other abbreviations as in Table 1.

Risk of Event (\%)

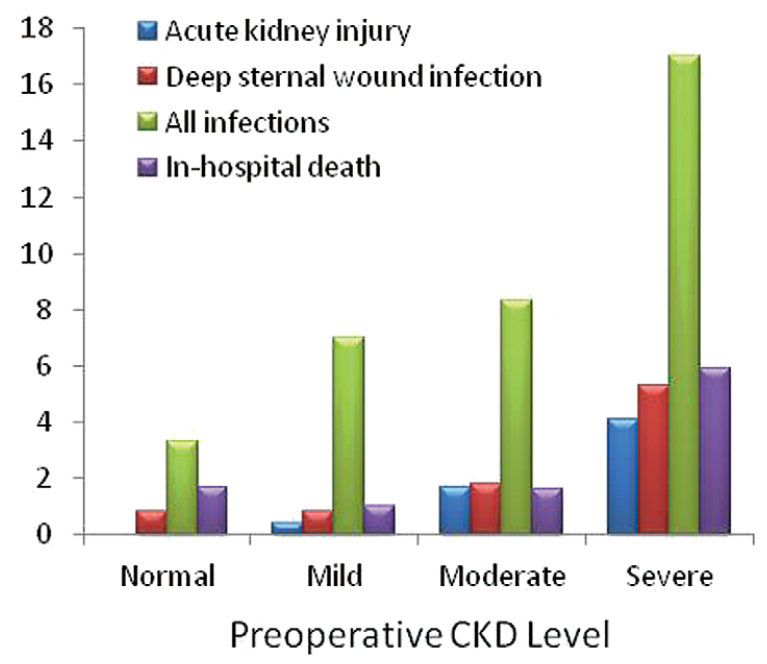

Ventilator time (hour)

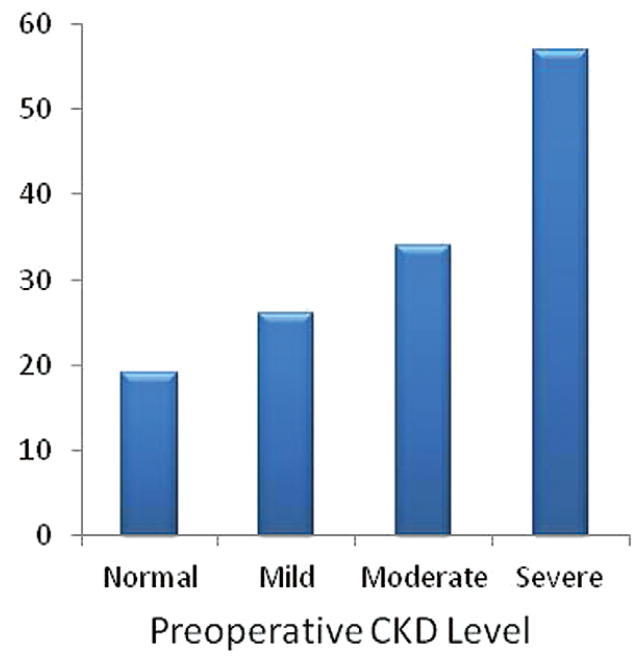

Figure. (Left) Risk of events and (Right) mean postoperative ventilator time vs. chronic kidney disease (CKD) level.

(methylprednisolone, 500-1,000 mg) was primed in the cardiopulmonary bypass circuit in some centers for on-pump CABG patients. Also, some surgeons and anesthesiologists preferred to give a moderate amount of i.v. steroid (methylprednisolone $125-500 \mathrm{mg}$ ) immediately after starting off-pump CABG in order to prevent systemic inflammatory response.

Postoperative variables were acute myocardial infarction, cerebrovascular events, acute kidney injury and other cardiovascular events (including cardiac tamponade, ventricular tachycardia or fibrillation, and complications after percutaneous coronary intervention). Acute kidney injury was defined as increased creatinine $>2$-fold preoperative baseline level and $\geq 2.0 \mathrm{mg} / \mathrm{dl}$, or newly requiring HD. Postoperative infection was defined as a composite of deep sternal wound infection (anterior mediastinitis), superficial sternal wound infection, graft harvesting site infection, bloodstream infection, urinary tract infection, and pneumonia. In-hospital death included all-cause death within 30 days of operation or during initial hospitalization.

\section{Statistical Analysis}

Baseline patient characteristics according to preoperative CKD level are given as mean \pm SD for continuous variables and proportions for categorical variables. They were compared with trend tests using univariate general linear models and with the chi-squared test, respectively.

Logistic regression analysis was conducted to estimate the effect of CKD (moderate CKD, and severe CKD as compared to normal or mild CKD as the reference group) on the risks of acute kidney injury, all infection, and all-cause death with the following potential adjustment factors: DM, age, gender, hypertension, dyslipidemia, body mass index, congestive heart failure, chronic obstructive pulmonary disease (COPD), periph- 


\begin{tabular}{lrrr|}
\hline Table 3. Multivariate Predictors of Acute Kidney Injury & & & \\
& OR & $\mathbf{9 5 \%}$ Cl & P-value \\
Moderate CKD (vs. normal or mild CKD) & 5.10 & $1.06-24.60$ & 0.04 \\
Severe CKD (vs. normal or mild CKD) & 14.82 & $3.02-72.84$ & $<0.01$ \\
Age (10-year increments) & 2.30 & $1.16-4.57$ & 0.02 \\
Urgent (vs. elective) & 4.02 & $1.31-12.32$ & 0.01 \\
Emergency (vs. elective) & 3.85 & $0.80-18.60$ & 0.09 \\
\hline
\end{tabular}

$\mathrm{Cl}$, confidence interval; OR, odds ratio. Other abbreviation as in Table 1.

\begin{tabular}{|c|c|c|c|}
\hline & OR & $95 \% \mathrm{Cl}$ & P-value \\
\hline Moderate CKD (vs. normal or mild CKD) & 1.04 & $0.65-1.67$ & 0.87 \\
\hline Severe CKD (vs. normal or mild CKD) & 2.48 & $1.44-4.27$ & $<0.01$ \\
\hline DM (vs. normal) & 1.23 & $0.82-1.85$ & 0.32 \\
\hline Age (10-year increments) & 1.02 & $0.81-1.28$ & 0.90 \\
\hline Male gender (vs. female) & 0.60 & $0.38-0.93$ & 0.02 \\
\hline Hypertension (vs. normal) & 1.01 & $0.63-1.61$ & 0.97 \\
\hline Dyslipidemia (vs. normal) & 0.67 & $0.44-1.01$ & 0.05 \\
\hline BMI (1-unit increments) & 1.06 & $1.00-1.12$ & 0.06 \\
\hline $\mathrm{CHF}$ (vs. normal) & 0.88 & $0.48-1.63$ & 0.69 \\
\hline COPD (vs. normal) & 1.95 & $1.05-3.61$ & 0.03 \\
\hline PAD (vs. normal) & 0.93 & $0.56-1.54$ & 0.78 \\
\hline LVEF $<50 \%$ (vs. $\geq 50 \%$ ) & 1.35 & $0.86-2.12$ & 0.20 \\
\hline BITA use (vs. no use) & 1.57 & $1.02-2.42$ & 0.04 \\
\hline Off-pump (vs. on-pump) & 0.53 & $0.33-0.84$ & 0.01 \\
\hline Urgent (vs. elective) & 1.14 & $0.57-2.29$ & 0.70 \\
\hline Emergency (vs. elective) & 1.29 & $0.47-3.50$ & 0.62 \\
\hline Intraoperative steroid use (vs. no use) & 0.62 & $0.39-0.97$ & 0.04 \\
\hline
\end{tabular}

BITA, bilateral internal thoracic artery. Other abbreviations as in Tables 1,3.

\begin{tabular}{|c|c|c|c|}
\hline & OR & $95 \% \mathrm{Cl}$ & P-value \\
\hline Moderate CKD (vs. normal or mild CKD) & 1.26 & $0.47-3.35$ & 0.65 \\
\hline Severe CKD (vs. normal or mild CKD) & 3.29 & $1.26-8.63$ & 0.02 \\
\hline Diabetes mellitus (vs. normal) & 2.13 & $0.90-5.03$ & 0.09 \\
\hline Dyslipidemia (vs. normal) & 0.31 & $0.13-0.74$ & $<0.01$ \\
\hline CHF (vs. normal) & 3.37 & $1.50-7.60$ & $<0.01$ \\
\hline COPD (vs. normal) & 3.91 & $1.50-10.56$ & $<0.01$ \\
\hline Off-pump (vs. on-pump) & 0.30 & $0.13-0.68$ & $<0.01$ \\
\hline
\end{tabular}

Abbreviations as in Tables 1,3.

eral artery disease, left ventricular ejection fraction $(<50 \%)$, bilateral ITA (BITA) use, off-pump technique, operative status (elective vs. urgent or emergency), and intraoperative steroid use. The number of acute kidney injury and of all-cause deaths in this study was low and we therefore screened the adjustment factors in logistic regression analysis of these outcomes through a backward variable selection procedure with a critical value of $\mathrm{P}<0.1$. Odds ratios $(\mathrm{OR})$ and their associated $95 \%$ confidence intervals were calculated. All reported P-values are 2-sided and the significance level was set at $5 \%$. All statistical analysis was done by an academic statistician (S. Tanaka) using SAS version 9.3 (SAS Institute, Cary, NC, USA).

This study was approved by the Internal Review Board at all the participating hospitals and the Ethics Committee of the Kyoto University Graduate School and Faculty of Medicine.
All the patients and their families gave written consent at the time of operation for participation in the JACVSD.

\section{Results}

A total of 1,522 enrolled patients were classified into 4 groups according to preoperative kidney function level: normal, $\mathrm{n}=121$ (8\%); mild CKD, $\mathrm{n}=713$ (47\%); moderate CKD, $\mathrm{n}=515$ (34\%); and severe CKD, $\mathrm{n}=169(11 \%)$. Of note, 4 patients were excluded from the original cohort due to lack of creatinine data. Patient baseline characteristics are listed in Table 1 . The mean age in the normal group was significantly younger than that in the other groups. Patients older than 75 years were most numerous in the moderate CKD group $(36.7 \%)$. The prevalence of systemic hypertension, DM, peripheral arterial disease, and 


\begin{tabular}{|c|c|c|c|}
\hline \multicolumn{4}{|c|}{$\begin{array}{l}\text { Table 6. Severe CKD Baseline Characteristics vs. Need for } \\
\text { HD }\end{array}$} \\
\hline \multirow{2}{*}{ Variables } & \multicolumn{2}{|c|}{ Severe CKD (n=169) } & \multirow{2}{*}{ P-value } \\
\hline & HD (-) $(n=85)$ & HD (+) $(n=84)$ & \\
\hline Age (years) & $71.9 \pm 7.9$ & $66.4 \pm 8.8$ & $<0.01$ \\
\hline Age $\geq 75$ & $31(36.5)$ & $14(16.7)$ & $<0.01$ \\
\hline Male gender & $57(67.1)$ & $67(79.8)$ & 0.06 \\
\hline eGFR $\left(\mathrm{ml} \cdot \mathrm{min}^{-1} \cdot 1.73 \mathrm{~m}^{-2}\right)$ & $22.0 \pm 5.7$ & $6.7 \pm 3.5$ & $<0.01$ \\
\hline $\mathrm{BMI}\left(\mathrm{kg} \cdot \mathrm{m}^{-2}\right)$ & $23.6 \pm 3.2$ & $22.5 \pm 3.8$ & 0.04 \\
\hline Hypertension & $71(83.5)$ & $71(84.5)$ & 0.86 \\
\hline Dyslipidemia & $43(50.6)$ & 28 (33.3) & 0.02 \\
\hline $\mathrm{DM}$ & $57(67.1)$ & $55(65.5)$ & 0.83 \\
\hline On insulin & $23(27.1)$ & 27 (32.1) & \\
\hline Preoperative HbA1c (\%) & $6.3 \pm 1.1$ & $5.7 \pm 1.1$ & $<0.01$ \\
\hline Preoperative steroid use & $3(3.5)$ & $3(3.6)$ & 0.99 \\
\hline $\mathrm{CHF}$ & $23(27.1)$ & $21(25.0)$ & 0.76 \\
\hline COPD & $15(17.6)$ & $6(7.1)$ & 0.04 \\
\hline PAD & $29(34.1)$ & $28(33.3)$ & 0.91 \\
\hline LVEF $<50 \%$ & $29(34.1)$ & $20(23.8)$ & 0.14 \\
\hline \multicolumn{4}{|l|}{ Operative status } \\
\hline Elective & $68(80.0)$ & 64 (76.2) & 0.50 \\
\hline Urgent & $12(14.1)$ & $12(14.3)$ & \\
\hline Emergency & $5(5.9)$ & $8(9.5)$ & \\
\hline BITA use & $31(36.5)$ & $26(31.0)$ & 0.45 \\
\hline Intraoperative steroid use & $21(24.7)$ & $32(38.1)$ & 0.06 \\
\hline \multicolumn{4}{|l|}{ On-pump or off-pump } \\
\hline On-pump & $20(23.5)$ & $34(40.5)$ & 0.02 \\
\hline On-pump beating & $3(3.5)$ & $3(3.6)$ & \\
\hline Off-pump & $62(72.9)$ & $47(56.0)$ & \\
\hline
\end{tabular}

Data given as mean \pm SD or $n(\%)$. HD, hemodialysis. Other abbreviations as in Tables 1,4.

congestive heart failure were correlated with elevated CKD, but there were no significant differences observed for preoperative hemoglobin A1c, prevalence of dyslipidemia, COPD, or status of operation (elective vs. emergency) among the groups. Preoperative oral steroid use was most common in the severe CKD group. BITA were used in the majority of patients in the normal and mild CKD groups (both $>50 \%$ ), but BITA use was less common in the severe CKD group $(33.7 \%, \mathrm{P}<0.01)$. In addition, the off-pump technique was less frequently used in the severe CKD group (64.5\%) compared to the other groups (all $>70 \%$ ) although this was not statistically significant.

Perioperative adverse events are listed in Table 2. Although there were no correlations in terms of perioperative myocardial infarction and cerebrovascular accident, the risks of acute kidney injury, all infections including anterior mediastinitis, and in-hospital death increased significantly as CKD progressed (Figure). In addition, postoperative mechanical ventilator support time became significantly longer as CKD progressed. Notably, the risk of infection was more than double even in the mild CKD group (7.0\%) and more than 5-fold in the severe CKD group (17\%), compared to that in the normal group (3.3\%). The in-hospital mortality rate was extremely high in the severe CKD group $(5.9 \%)$ compared to that in the other groups $(<2 \%)$. Of note, there were too few events in each subgroup to conduct any meaningful statistical analysis of the data in Table 2.

Multivariate logistic regression results are listed in Tables 3-5. Moderate $\mathrm{CKD}$ and severe $\mathrm{CKD}$ were found to be very strong

\begin{tabular}{|ccc|}
\hline \multirow{2}{*}{ Table 7. Adverse Events in Severe CKD vs. Need for HD } \\
Events and outcomes & \multicolumn{2}{c|}{ Severe CKD ( $\mathbf{n}=\mathbf{1 6 9})$} \\
\cline { 2 - 3 } Perioperative MI & $\mathbf{H D}(\mathbf{n}=\mathbf{8 5})$ & HD (+) (n=84) \\
Related death & 0 & $2(2.4)$ \\
Cerebrovascular events & 0 & 0 \\
Related death & $1(1.2)$ & 0 \\
Other cardiovascular events & 0 & 0 \\
Related death & $2(2.4)$ & $1(1.2)$ \\
Deep sternal wound infection & $3(3.5)$ & 0 \\
All infection & $14(16.5)$ & $6(7.1)$ \\
Related death & $4(4.7)$ & $4(16.7)$ \\
Postoperative ventilator time (h) & $59.4^{\dagger}$ & $54.1^{\dagger}$ \\
In-hospital death & $6(7.1)$ & $4(4.8)$ \\
\hline
\end{tabular}

Data given as $\mathrm{n}(\%)$ or tmean. Abbreviations as in Tables 1,2,6.

predictors for risk of postoperative acute kidney injury (OR, 5.10, $\mathrm{P}=0.04$ and $\mathrm{OR}, 14.82, \mathrm{P}<0.01$, respectively). Also, advanced age was a significant predictor for acute kidney injury $(\mathrm{OR}, 2.30 ; \mathrm{P}=0.02)$. With regard to all infections (Table 4), the significant risk factors were severe $\mathrm{CKD}(\mathrm{OR}, 2.48 ; \mathrm{P}<0.01)$ and COPD (OR, 1.95; $\mathrm{P}=0.03)$. Also, the use of BITA was found to be a risk factor for infection $(\mathrm{OR}, 1.57 ; \mathrm{P}=0.04)$. In contrast, male gender (OR, $0.60 ; \mathrm{P}=0.02)$, off-pump technique $(\mathrm{OR}, 0.53 ; \mathrm{P}=0.01)$, and intraoperative steroid use (OR, 0.62; $\mathrm{P}=0.04)$ were protective factors for infection. As shown in Table 5, the significant risk factors for in-hospital death were severe $\mathrm{CKD}(\mathrm{OR}, 3.29 ; \mathrm{P}=0.02)$, congestive heart failure $(\mathrm{OR}$, 3.37; $\mathrm{P}<0.01)$, and COPD (OR, 3.91; $\mathrm{P}<0.01)$ on multivariate analysis. Of note, off-pump technique $(\mathrm{OR}, 0.30 ; \mathrm{P}<0.01)$ was identified as a protective factor against in-hospital death.

In the severe CKD group, 84 patients were dependent on HD preoperatively. We divided these severe CKD patients into 2 subgroups: HD dependent (HD subgroup, $n=84$ ) and those who were not (non-HD subgroup, $n=85$ ). Baseline patient characteristics are listed in Table 6. Mean eGFR was $22.0 \mathrm{ml} \cdot \mathrm{min}^{-1} \cdot 1.73 \mathrm{~m}^{-2}$ in the non-HD subgroup and $6.7 \mathrm{ml} \cdot \mathrm{min}^{-1} \cdot 1.73 \mathrm{~m}^{-2}$ in the HD subgroup. HD patients were much younger, and male gender was more predominant. There was no difference in the prevalence of hypertension or DM between these subgroups, but preoperative hemoglobin A1c was significantly higher in the non-HD patients than in the HD patients $(6.3 \%$ vs. $5.7 \%, \mathrm{P}<0.01)$. Also, prevalence of COPD was much higher in the non-HD subgroup. Notably, the offpump technique was less commonly used in the HD subgroup than in the non-HD subgroup (56.0\% vs. $72.9 \%$ ), although this was not statistically significant. Perioperative adverse events are listed in Table 7. Cardiovascular adverse events were rare, but all infections were common in both subgroups. In particular, deep sternal wound infection was more common in the HD subgroup $(n=6,7.1 \%)$ than in the non-HD subgroup $(n=3$, $3.5 \%$ ). In contrast, in-hospital mortality was somewhat higher in the non-HD subgroup $(n=6,7.1 \%)$ than in the HD subgroup $(n=4,4.8 \%)$. Statistical analysis between 2 subgroups was not performed because there were too few events and the patient clinical features were so different.

\section{Discussion}

It is widely recognized that preoperative CKD is common among patients who require both surgical and interventional 
coronary revascularization. A large-scale cohort study using the STS National database in the USA found that $51 \%$ of CABG patients had mild CKD, 24\% had moderate CKD, $2 \%$ had severe CKD (excluding HD), and $1.5 \%$ of patients were HD dependent. ${ }^{15}$ The prevalence of mild CKD in the current study $(47 \%)$ was similar to that of the STS database, but the prevalence of moderate CKD and severe CKD including HD was higher in the present study, found in $34 \%$ and $11 \%$ of patients, respectively, than in the STS database (24\% and $2.5 \%$ ). In general, the prevalence of DM increases significantly as CKD advances. In the STS database, the prevalence of DM was $29.5 \%$ in the normal group, $25.8 \%$ in the mild CKD group, $35.3 \%$ in the moderate CKD group, and $62.6 \%$ in the severe CKD group. The prevalence of DM was lower in the STS database study at each CKD level compared to the present cohort (Table 1). In contrast, there were no significant differences in age or prevalence of peripheral artery disease between the 2 cohorts. This may reflect the fact that we Japanese cardiac surgeons are dealing with a more severely affected patient in current practice.

In terms of postoperative complications, the risk of cardiovascular events, including perioperative cerebrovascular accident and myocardial infarction, was not significantly correlated with preoperative CKD level. The risk of all infection, however, was strongly correlated with CKD level. Importantly, in even mild CKD patients, the risk of infection was more than double that in the normal group. Furthermore, the risk of infection was more than 5-fold higher in severe CKD patients than in normal patients. Accordingly, the risk of deep sternal wound infection was much higher in moderate and severe CKD patients. On multivariate analysis, severe CKD was found to be an independent predictor for infection (OR, 2.48; $\mathrm{P}<0.01$ ). In addition to severe CKD, COPD and BITA use were identified as risk factors for infection on multivariate analysis $(\mathrm{OR}, 1.95, \mathrm{P}=0.03$ and $\mathrm{OR}, 1.57, \mathrm{P}=0.04$, respectively). In general, we have been very aggressive in using BITA. In the present study, the majority of normal and mild CKD patients received BITA grafting. As shown in Table 1, BITA use was significantly lower in the moderate and severe CKD groups. Although the use of BITA in high-risk patients with moderate or severe CKD had apparently been limited, BITA use still emerged as a risk factor for infection. The risk of in-hospital death was acceptable in the normal, mild, and moderate CKD groups (all <2\%), but in-hospital mortality was extremely high $(5.9 \%)$ in the severe CKD group. These results are consistent with those of other studies. ${ }^{16-19}$ In the current study, the majority of deaths in severe CKD patients were related to infection (80\%; Table 2). More strict intra- and postoperative blood glucose control might have reduced the risk of infection and in-hospital mortality, especially in the moderate and severe CKD groups,${ }^{20}$ although we were not able to identify an influence of postoperative blood glucose control level on postoperative infection in the previous analysis. ${ }^{13}$

It is now evident that CKD level has a significant impact on CABG outcome. ${ }^{15,21}$ In particular, severe CKD is associated with much higher morbidity and mortality; but despite having analyzed the differences between the HD and non-HD patients in the severe CKD group, it is still unclear how preoperative HD status influences CABG outcome. As shown in Table 6, baseline characteristics were very different between the HD and non-HD subgroups. ${ }^{22}$ This may indicate that the HD subgroup was more heterogeneous. In fact, ESRD requiring HD could be caused by either DM nephropathy or other kidney disease such as chronic glomerulonephritis. Obviously, those patients with chronic glomerulonephritis tend to be relatively young, non-diabetic, and have less likelihood of complications involving severe atherosclerotic disease of the carotid and/or peripheral arteries, and would be expected to have better longterm survival. In terms of postoperative complications, infection was very common in both groups. Importantly, deep sternal wound infection was higher in the HD subgroup (7.1\%) than that in non-HD subgroup (3.5\%), but in-hospital mortality was higher in the non-HD subgroup (7.1\%) than that in HD subgroup (4.8\%). It is possible that non-HD severe CKD patients are more likely to develop acute kidney injury after surgery, subsequently requiring HD. During the period of intensive care, including renal replacement therapy, non-HD severe CKD patients may be more likely to develop infections through a vascular access or a mechanical ventilator. Although the lack of detailed analysis precludes further discussion of results in this regard, it appears that non-HD severe CKD patients have at least as bad a short- and long-term prognosis as HD patients. ${ }^{15,18,23}$ Cooper et al found that the use of ITA lessened operative mortality in both non-HD severe CKD patients and HD patients. ${ }^{15}$ In addition, Nakayama et al showed that BITA use might improve long-term survival in HD patients undergoing $\mathrm{CABG} .{ }^{23}$ Further study however, failed to demonstrate an advantage of BITA grafting for long-term outcome. ${ }^{24}$ Decisions regarding use of BITA should always weigh the longterm benefits vs. the risk of deep sternal wound infection, which directly affects short-term outcome, in each patient.

In Japan, the off-pump technique is very commonly used when performing CABG. ${ }^{25}$ In a prospective randomized study, Modine et al found that the off-pump technique lessens subclinical acute kidney injury in DM patients undergoing CABG. ${ }^{26}$ The incidence of postoperative acute kidney injury was very low in the normal and mild CKD groups in the present study, whereas $1.7 \%$ and $4.1 \%$ of patients developed this complication in the moderate and severe CKD groups, respectively. Our aggressive use of the off-pump technique may have resulted in this low incidence of acute kidney injury, given the fact that approximately $10 \%$ of severe CKD patients required HD after surgery in the STS database. In HD patients, however, it appears that surgeons tended to be less aggressive in using the off-pump technique, likely due to the presence of more severe CADs such as diffuse, calcified and complex lesions. On multivariate analysis, off-pump technique was found to be a protective factor for risk of infection and in-hospital death. Dewey et al showed that off-pump CABG improved the early mortality rate compared to on-pump CABG in HD patients, but longterm survival was better in the on-pump CABG group. ${ }^{27}$ Also, Boulton et al showed that long-term survival was significantly lower in off-pump CABG in patients with mild to moderate CKD compared to that of on-pump CABG ${ }^{28}$ Surgeons should keep in mind that complete revascularization in patients undergoing $\mathrm{CABG}$ always yields a survival benefit.

\section{Study Limitations}

There are several limitations to this study. This was a retrospective, observational study, so the various unknown patient selection processes may have caused a bias. The definition of CKD was based only on preoperative eGFR, not evaluated with baseline diseases or presence of proteinuria. Although the total number of patients was sufficient to analyze the influence of CKD level as a predictor of in-hospital mortality and risk of infection, it was not sufficiently large to allow detailed subgroup analysis between HD and non-HD patients in order to identify the impact of HD. Also, this study was based on posthoc analyses, and was not designed to evaluate long-term outcome, which may be more important to assess the true influ- 
ence of preoperative CKD level.

\section{Conclusions}

Preoperative $\mathrm{CKD}$ was very common in patients undergoing $\mathrm{CABG}$, and advanced CKD was a strong predictor of postoperative infection, acute kidney injury and in-hospital death.

\section{Acknowledgments}

We are indebted to the participating centers, investigators and clinical research coordinators for their great contributions to data collection. Participating cardiac surgery centers were Iwate Medical University, Jichi Medical University, Sakakibara Heart Institute, Nagoya University Hospital, Handa City Hospital, Kyoto University Hospital, University Hospital Kyoto Prefectural University of Medicine, Kobe University Hospital, Kobe City Medical Center General Hospital, Tominaga Hospital, Wakayama Medical University Hospital, Kawasaki Medical School Hospital, Kurume University Hospital, and Kagoshima University Hospital.

\section{Disclosures}

Source of Funding: This study was supported by a Health and Labour Science Research Grant from the Ministry of Health, Labour and Welfare of Japan (Grant ID: 09158533).

\section{References}

1. Gupta R, Birnbaum Y, Uretsky BF. The renal patient with coronary artery disease: Current concepts and dilemmas. J Am Coll Cardiol 2004; 44: $1343-1353$.

2. Manjunath G, Tighiouart H, Ibrahim H, MacLeod B, Salem DN, Griffith JL, et al. Level of kidney function as a risk factor for atherosclerotic cardiovascular outcomes in the community. J Am Coll Cardiol 2003; 41: 47-55.

3. Briasoulis A, Bakris GL. Chronic kidney disease as a coronary artery disease risk equivalent. Curr Cardiol Rep 2013; 15: 340-346.

4. Anavekar NS, McMurray JJ, Velazquez EJ, Solomon SD, Kober L, Rouleau JL, et al. Relation between renal dysfunction and cardiovascular outcomes after myocardial infarction. N Engl J Med 2004; 351: $1285-1295$.

5. Go AS, Chertow GM, Fan D, McCulloch CE, Hsu CY. Chronic kidney disease and the risks of death, cardiovascular events, and hospitalization. N Engl J Med 2004; 351: 1296-1305.

6. Hedayati SS, Szczech LA. The evaluation of underlying cardiovascular disease among patients with end-stage renal disease. Adv Chronic Kidney Dis 2004; 11: 246-253.

7. Ohsawa M, Tanno K, Itai K, Turin TC, Okamura T, Ogawa A, et al. Comparison of predictability of future cardiovascular events between chronic kidney disease (CKD) stage based on CKD epidemiology collaboration equation and that based on modification of diet in renal disease equation in the Japanese general population: Iwate KENCO Study. Circ J 2013; 77: 1315-1325.

8. Leavitt BJ, Sheppard L, Maloney C, Clough RA, Braxton JH, Charlesworth DC, et al. Effect of diabetes and associated conditions on long-term survival after coronary artery bypass graft surgery. Circulation 2004; 110(Suppl 1): II41-II44.

9. Abboud H, Henrich WL. Clinical practice: Stage IV chronic kidney disease. $N$ Engl J Med 2010; 362: 56-65.

10. Himmelfarb J, Ikizler TA. Hemodialysis. N Engl J Med 2010; 363: $1833-1845$.

11. Domoto S, Tagusari O, Nakamura Y, Takai H, Seike Y, Ito Y, et al. Preoperative estimated glomerular filtration rate as a significant pre- dictor of long-term outcomes after coronary artery bypass grafting in Japanese patients. Gen Thorac Cardiovasc Surg 2012; 62: 95-102.

12. Tanaka S, Sakata R, Marui A, Furukawa Y, Kita T, Kimura T, et al. Predicting long-term mortality after first coronary revascularization: The Kyoto model. Circ J 2012; 76: 328-334.

13. Minakata K, Bando K, Takanashi S, Konishi H, Miyamoto Y, Ueshima $\mathrm{K}$, et al. Impact of diabetes mellitus on outcomes in Japanese patients undergoing coronary artery bypass grafting. J Cardiol 2012; 59: $275-284$.

14. Matsuo S, Imai E, Horio M, Yasuda Y, Tomita K, Nitta K, et al. Revised equations for estimated GFR from serum creatinine in Japan. Am J Kidney Dis 2009; 53: 982-992.

15. Cooper WA, O'Brien SM, Thourani VH, Guyton RA, Bridges CR, Szczech LA, et al. Impact of renal dysfunction on outcomes of coronary artery bypass surgery: Results from the Society of Thoracic Surgeons National Adult Cardiac Database. Circulation 2006; 113: $1063-1070$.

16. Charytan DM, Yang SS, McGurk S, Rawn J. Long and short-term outcomes following coronary artery bypass grafting in patients with and without chronic kidney disease. Nephrol Dial Transplant 2010; 25: $3654-3663$.

17. Holzmann MJ, Ahnve S, Hammar N, Jörgensen L, Klerdal K, Pehrsson $\mathrm{K}$, et al. Creatinine clearance and risk of early mortality in patients undergoing coronary artery bypass grafting. $J$ Thorac Cardiovasc Surg 2005; 130: 746-752.

18. Yeo KK, Li Z, Yeun JY, Amsterdam E. Severity of chronic kidney disease as a risk factor for operative mortality in nonemergent patients in the California coronary artery bypass graft surgery outcomes reporting program. Am J Cardiol 2008; 101: 1269-1274.

19. Zakeri R, Freemantle N, Barnett V, Lipkin GW, Bonser RS, Graham TR, et al. Relation between mild renal dysfunction and outcomes after coronary artery bypass grafting. Circulation 2005; 112 (Suppl): I270I275.

20. Furnary AP, Gao G, Grunkemeier GL, Wu Y, Zerr KJ, Bookin SO, et al. Continuous insulin infusion reduces mortality in patients with diabetes undergoing coronary artery bypass grafting. J Thorac Cardiovasc Surg 2003; 125: $1007-1021$.

21. Kinoshita T, Asai T, Murakami Y, Suzuki T, Kambara A, Matsubayashi K. Preoperative renal dysfunction and mortality after off-pump coronary artery bypass grafting in Japanese. Circ J 2010; 74: 1866-1872.

22. Natsuaki M, Furukawa Y, Morimoto T, Nakagawa Y, Akao M, Ono $\mathrm{K}$, et al. Impact of diabetes on cardiovascular outcomes in hemodialysis patients undergoing coronary revascularization. Circ J 2011; 75: $1616-1625$.

23. Nakayama Y, Sakata R, Ura M, Itoh T. Long-term results of coronary artery bypass grafting in patients with renal insufficiency. Ann Thorac Surg 2003; 75: 496-500.

24. Nakatsu T, Tamura N, Sakakibara Y, Hagio K, Ishigami M. Longterm survival after coronary arterial grafts in patients with end-stage renal disease. Ann Thorac Surg 2010; 90: 738-743.

25. Amano J, Kuwano H, Yokomise H. Thoracic and cardiovascular surgery in Japan during 2011. Gen Thorac Cardiovasc Surg 2013; 61: $578-607$.

26. Modine T, Zannis C, Salleron J, Provot F, Gourlay T, Duhamel A, et al. A prospective randomized study to evaluate the renal impact of surgical revascularization strategy in diabetic patients. Interact Cardiovasc Thorac Surg 2010; 11: 406-410.

27. Dewey TM, Herbert MA, Prince SL, Robbins CL, Worley CM, Magee MJ, et al. Does coronary artery bypass graft surgery improve survival among patients with end-stage renal disease? Ann Thorac Surg 2006; 81: 591-598.

28. Boulton BJ, Kilgo P, Guyton RA, Puskas JD, Lattouf OM, Chen EP, et al. Impact of preoperative renal dysfunction in patients undergoing off-pump versus on-pump coronary artery bypass. Ann Thorac Surg 2011; 92: 595-601. 